Published in final edited form as:

Cell Tissue Res. 2013 August ; 353(2): 231-244. doi:10.1007/s00441-013-1603-0.

\title{
Development of diagnostic and treatment strategies for glaucoma through understanding and modification of scleral and lamina cribrosa connective tissue
}

\author{
Harry A. Quigley and Frances E. Cone \\ Director, Glaucoma Center of Excellence, Wilmer Institute, Johns Hopkins University School of \\ Medicine, Baltimore, MD USA
}

\section{Abstract}

There is considerable evidence that the state of ocular connective tissues and their response in glaucomatous disease affects the degree of glaucoma damage. Both experimental and clinical data suggest that improved diagnostic and prognostic information could be derived from assessment of the mechanical responsiveness of the sclera and lamina cribrosa to intraocular pressure (IOP). Controlled mutagenesis of the sclera has produced a mouse strain that is relatively resistant to increased IOP. Alteration of the baseline scleral state could be accomplished through either increased cross-linking of fibrillar components or their reduction. The sclera is a dynamic structure, altering its structure and behavior in response to IOP change. The biochemical pathways that control these responses are fertile areas for new glaucoma treatments.

\section{Keywords}

glaucoma; sclera; pathogenesis; retinal ganglion cell; therapy

\section{Introduction}

For over a century, we have recognized a link between the level of intraocular pressure (IOP) and glaucomatous optic nerve damage. In persons suffering abnormally high IOP, a change in optic nerve head (ONH) tissues described as excavation occurs, in parallel with progressive loss of visual field function. The change in the $\mathrm{ONH}$ is coincident with the death of retinal ganglion cells (RGC) and their axons in the retinal nerve fiber layer. No other retinal neurons die in glaucoma. When IOP is experimentally elevated in mammalian eyes, $\mathrm{ONH}$ and RGC changes quite similar to those in human disease occur. In every populationbased survey for open angle glaucoma (OAG), $50-80 \%$ of those with glaucoma damage have the same IOP levels seen in similar aged normal persons. Thus, many of those with OAG have risk factors that make their ONH and RGC susceptible to damage at IOP levels that are tolerated without clinical disease by most persons. Both mean intraocular pressure (IOP) level ${ }^{1}$ and IOP fluctuation ${ }^{2}$ are closely associated with incident human glaucoma and its progressive worsening. However, the risk factor for glaucoma damage is the level of IOP, not only elevated IOP. Furthermore, lowering of IOP slows the progressive loss of RGC in both animal and human glaucoma ${ }^{3,4,5}$, whether the initial IOP is above the normal level or not.

In experimental animal models, non-IOP lowering neuroprotective treatments have been reported $6,7,8,9,10,11,12$, largely aimed at slowing RGC body and axon death after injury has begun. Logically, neuroprotective treatments would be most effective at preventing RGC injury from entering an irretrievable phase, by acting at the earliest stage of damage. Once RGC body or axon disruption begins, restoration of normal RGC structure and function are 
less likely. The purpose of this report is to detail features of the ocular response to IOP (normal and elevated) that are likely to participate in glaucoma, to suggest potential candidate genes that may be diagnostically useful, and to indicate a new therapeutic approach to altering these responses beneficially.

\section{Ocular connective tissues mediate IOP effects}

IOP-generated stress affects the optic nerve head $(\mathrm{ONH})$ in at least two ways. First, there is a pressure differential across the ONH (IOP minus retrobulbar optic nerve tissue pressure). Second, IOP-related stress in the eye wall (cornea and sclera) is transmitted to the ONH by circumferential (hoop) stress at its margins (Figure 1). These stresses ultimately contribute to permanent deformation of ONH tissues, called excavation or cupping (Figure 2 and 3), which is a key clinical feature of human glaucoma that differentiates it from other optic neuropathies ${ }^{13}$. ONH deformation affects its RGC axons, astrocytes, blood vessels, and (in non-human primates and human eyes) the $\mathrm{ONH}$ connective tissues. Associated with these alterations, anterograde and retrograde axonal transport at the ONH are interrupted in RGC. Coincident with this interruption, axon degeneration at begins at the $\mathrm{ONH}$, and capillaries and glial defects are also observed at the same site. RGC death by apoptosis ${ }^{14,15}$ is associated with axonal transport blockade in $\operatorname{man}^{16}$, monkey(Figure 4$)^{17}$, and rodent eyes at the $\mathrm{ONH}^{18}$, and intra-retinal events at the RGC body occur rapidly after initial axon injury.

Substantial evidence points to the central role of ocular connective tissues in mediating human glaucoma damage. The $\mathrm{ONH}$ zones in which physical deformation is greatest are those that suffer more RGC axon injury. The preferential loss of the RGC whose axons pass through the superior and inferior portions of the $\mathrm{ONH}$ explains the typical pattern of earlymoderate visual field defects seen in glaucoma, $\left(\right.$ Figure 5) ${ }^{19}$. Second, persons with axial myopia are more susceptible to $\mathrm{OAG}^{20}$ and their eyes have mechanical disadvantages in responding to the stress of IOP due to their larger globe diameter and thinner sclera. Third, hysteresis measured by Ocular Response Analyser is a risk factor for open angle glaucoma $(\mathrm{OAG})$ progression ${ }^{21}$. Fourth, in human OAG patients, scleral rigidity is estimated to be increased by 2 different, indirect in vivo methods. ${ }^{22,23} \mathrm{Fifth}$, in post-mortem inflation studies, the scleral stiffness of OAG eyes is greater than that of age-matched controls ${ }^{24}$. There is no doubt that vascular, glial and immune factors contribute to RGC death in glaucoma. Axon injury and RGC loss in glaucoma are associated with disequilibrium in normal functions caused by direct fiber compression ${ }^{25}$, failure of normal capillary nutrition ${ }^{26}$, and astrocyte activation ${ }^{27}$. The contribution of IOP-generated stress to glaucoma is supported by abundant evidence and is potentially amenable to therapeutic intervention.

Studies of scleral anatomy and physiology are feasible and are highly relevant to what occurs in the ONH. The connective and supporting tissues adjacent to RGC axons in the ONH make up the beams of the lamina cribrosa itself. But, the ONH is a complex and relatively small structure, so testing its internal mechanical behavior is only indirectly feasible ${ }^{28}$. Biomechanical models ${ }^{29,30}$ suggest that the IOP-generated force transmitted to the $\mathrm{ONH}$ at its periphery by scleral stress is a critical element in producing strain at the $\mathrm{ONH}^{31}$. Sigal et al reported that the behavior of the $\mathrm{ONH}$ is strongly dependent on biomechanical properties of the peripapillary sclera. Acute deformation of the $\mathrm{ONH}$ and the consequent strain may be less dependent on translaminar pressure difference than on the indirect effects of IOP on the sclera that are transferred to the ONH. The orientation of collagen and elastin within the $\mathrm{ONH}$ beams is entirely from periphery to center, not internal to external. Hence, either the major strain is from scleral edge to opposite scleral edge, or, the translaminar strain must by borne by fibers whose course is perpendicular to the direction of stress. Individual variations in scleral state and its response are thus likely to be important glaucoma risk factors. Downs and co-workers corroborated that the biomechanical 
response of the posterior sclera is an important determinant of strain at the $\mathrm{ONH}$ due to tight coupling between sclera and lamina ${ }^{32}$. Variations in scleral mechanical properties could be one explanation for the fact that half of those with open angle glaucoma (OAG) suffer injury in the normal IOP range ${ }^{33}$. The candidates for risk factors and genes that explain glaucoma damage would therefore include both baseline scleral behavior and alterations in its behavior induced by IOP-related stress. Scleral responses to IOP could be both detrimental and beneficial to RGC survival. This review will present information on the sclera: anatomically, molecularly, physiologically, and mechanically, using data from experimental mice and monkeys, as well as human eyes.

\section{Are animal models useful?}

Mouse IOP elevation models generate data relevant to human glaucoma and provide research avenues not possible in monkey or human eyes. Mammalian eyes that are subjected to experimental IOP increase undergo neuronal, glial, and associated tissue alterations (Figure 6), that are phenotypically similar to human glaucoma ${ }^{34,35,36}$. Furthermore, lowering of IOP slows the progressive loss of RGC in both animal ${ }^{37}$ and human glaucoma. While mouse eyes differ in details of $\mathrm{ONH}$ anatomy from primates, they share the site of glaucoma injury and the selective death of RGC. Jakobs et al. ${ }^{38}$ demonstrated that astrocytes in the mouse ONH simulate the structure of the collagenous lamina cribrosa in monkey and human eyes, potentially transferring scleral wall tension to $\mathrm{ONH}$ axons and capillaries. The mouse sclera has collagens, elastin, and other molecules, as in human sclera ${ }^{39}$, though its thickness and diameter are 10 times smaller than human eyes ${ }^{40}$. Biophysical analysis shows that the $3 \mathrm{~mm}$ long mouse eye needs only one-eighth the scleral thickness of the $24 \mathrm{~mm}$ human eye to sustain similar biomechanical stress. While mouse eyes increase their axial length with chronic IOP increase, so do adult rats and monkeys, as well as human infants with chronic glaucoma. Thus, it is likely that studies of experimental rodent glaucoma ${ }^{41}$ provide relevant data on potential new diagnostic and therapeutic approaches in human eyes. Some experimental glaucoma model studies artificially raised IOP in rodents by obstruction of aqueous outflow, while others used genetically altered strains that develop IOP elevation $42,43,44,45,46,47,48$. These mouse strains could be informative not only on the effect of IOP on RGCs, but on the effect of modified connective tissues on susceptibility to damage. Studies of post-mortem human tissue document the actual disease, but in human histological material we cannot know the state of the sclera prior to glaucoma damage. Experimental monkey glaucoma has provided valuable information, but non-human primates cannot be studied in large numbers and do not allow study of the effects of the selective genetic alterations that are possible in mice. Experimental mouse glaucoma has already begun to validate the role of scleral structure and its response to chronic IOP elevation in ways not possible with other approaches.

\section{What scleral properties might be beneficial in glaucoma? Macroscopic scleral properties}

While eyes of any size can suffer from glaucoma, persons with larger eyes (typically with myopic refractive error) are more susceptible to OAG. A variety of reasons for this greater risk could be postulated, but one of the more obvious is the fact from simple physics that a globe of larger diameter has greater stress in its wall than a smaller one, all other things equal. Furthermore, it is known that things aren't equal, since myopic (axially longer) eyes have thinner sclera. Again, if the tensile properties of two scleral walls are equal, a thinner sclera would be expected to have less ability to withstand the stress of IOP. Thus, a theoretical argument can be made that smaller eyes with thicker sclera would be less likely to suffer injury. But, the composition of the sclera is quite complex at a microscopic level. 


\section{Microscopic fibrillar structure}

The sclera consists of a variety of extracellular macromolecules, dominated by type 1 collagen. There are, in addition, a variety of other collagens, elastin, proteoglycans, and scleral fibroblasts, which occupy about $10 \%$ of the sclera by volume in quantitative histological examinations. The collagen is organized in layers or lamellae that have most fibers oriented in the same direction, with successive lamellae alternating between orientations of front to back, side to side, or oblique (Figure 7). One analogy that decribes its general structure is that of basket-weave. In the mouse, the orientation of fiber lamellae in the mid-sclera is more often anterior to posterior than equatorial or oblique, with about 30 successive lamellae. By contrast with the cornea or the ONH's lamina cribrosa which have quite uniform collagen fibril diameters, the fibril diameter distribution of the sclera is diverse, and even varies between the outer, middle and inner sclera (nearest to the choroid; Figure 8).

This general pattern of basket-woven lamellae is not the case in the peripapillary zone nearest the $\mathrm{ONH}$. There, the fibrils are organized circumferentially around the $\mathrm{ONH}$. Not only are the collagen fibrils oriented in this way, but the peripapillary sclera has a complement of elastin, also running circumferentially (Figure 9), while the remainder of the sclera has only minimal elastin ${ }^{49,50,51,52,53}$. Detailed studies of the predominant, regional orientation of collagen fibrils shows this peripapillary ring ${ }^{54}$. By contrast, within the $\mathrm{ONH}$ of the monkey or human eye, fibrils of both collagen and elastin course from one side to the other in straight lines (Figure 10), probably in response to the stress generated in the peripapillary sclera to which the beams of the ONH connective tissue are attached. There are no fibrils oriented from inside to outside of the eye in the perpapillary sclera or ONH. Thus, the resistance to translaminar stress in the $\mathrm{ONH}$ or to stress in this direction in sclera must be borne by fibrils and lamellae that are perpendicular to this force.

While fibrillar components of the sclera are prominently seen in light and electron microscopy, the other molecular species present are both diverse and potentially important elements of its structure and response to stress. Key glycosaminoglycans that are present include heparan sulfate, chondroitin sulfate, dermatan sulfate, and keratan sulfate ${ }^{55}$.

\section{Glaucoma and sclera structural change}

In adult OAG, the sclera does not dramatically alter its length or thickness. The same cannot be said of infants with glaucoma or experimental animals, in which the length of the eye increases and the diameter of both the cornea and the $\mathrm{ONH}$ increase. The microscopic changes induced by experimental or human glaucoma in the peripapillary sclera and $\mathrm{ONH}$ are of interest in showing the response of the tissues to IOP-generated stress. The diameter distribution and orientation of fibrillar collagens in the $\mathrm{ONH}$ and peripapillary sclera are unchanged in human OAG eyes, though elastin is possibly degraded ${ }^{56}$ and definitely has an altered appearance (Figure 11) ${ }^{57}$, suggesting possible disruption of the intermolecular connections of elastin to the remainder of the connective tissue matrix.

In contrast to sclera, the $\mathrm{ONH}$ undergoes dramatic stretching, deepening and widening in glaucoma. In fact, the immediate peripapillary sclera also is altered, since the widening of the ONH involves lateral movement of the sclera. Recent studies of monkey eyes with chronic IOP elevation suggest that the process of early glaucoma damage includes the "recruitment" of connective tissue beams of the optic nerve posterior to the original lamina ${ }^{58}$. These are beams that are connected to the sclera indirectly through the pia mater, as indicated by fibrillary connections from the peripapillary ring (Figure 9B).

Age-related, ethnic, and genetic differences in scleral composition may contribute to glaucoma susceptibility. It is known that the axial length in older persons shortens and the 
sclera generally becomes thicker ${ }^{59}$. ONH and peripapillary scleral elastin differs between African-derived and European-derived persons, perhaps representing a risk factor for higher OAG prevalence in African-derived persons ${ }^{60}$. Mutations in the lysyl oxidase-like protein 1 (LOXL1) gene are associated with exfoliation glaucoma ${ }^{61}$, a subgroup in which differences from non-exfoliative eyes are found in posterior ocular connective tissues ${ }^{62}$.

\section{Biomechanical behavior of the sclera}

Until recently there was little information on relevant mechanical behavior of the eye under normal conditions or with glaucoma. Early studies used uniaxial testing of excised sclera between two metal grips ${ }^{63,64,65}$, but this approach is unlikely to reproduce ideally the behavior of the intact sclera. More recently, methods have been developed to determine the relationship between stress generated by artificially elevated IOP and strain in intact posterior eye globes in vitro for either eyes with experimental glaucoma or induced myopia in mouse ${ }^{66}$, tree shrew ${ }^{67}$, monkey ${ }^{68,69,70}$ and in human eyes ${ }^{24}$. The biomechanical response of connective tissue molecules in the sclera and $\mathrm{ONH}$ in glaucoma have been studied in monkeys with experimental glaucoma ${ }^{62}$. Human glaucoma donor eyes with RGC loss were measurably stiffer than controls, as were experimental mouse and monkey glaucoma eyes. This suggests that the effect of IOP on the sclera leads to its stiffening. It remains to be shown whether human eyes would be more or less susceptible to glaucoma damage if they were more compliant at baseline or stiffer at baseline. One hypothesis is that a more compliant sclera increases susceptibility to RGC loss. Under this scenario, the finding of stiffer sclera in post-mortem human glaucoma eyes after damage suggests that the stiffening is a protective response. We cannot determine at this time whether the stiffening in humans has a beneficial or a detrimental effect. A potential alternative hypothesis is that eyes are more susceptible to glaucoma when they are stiffer and become even stiffer as a result of the disease. This scenario would be the case if stiffness of the sclera actually intensifies strain within the ONH. Either hypothesis is compatible with existing human data. It is vital to determine which of the two alternatives (stiffer sclera being overall beneficial or detrimental) is the case, since this would provide the direction in which therapeutic change in sclera should go.

As with the scleral anatomy, regional differences in mechanical properties are present in normal eyes and provide important clues as to the forces acting on the tissue. Models that attempt to describe scleral behavior need further development. The basic data are typically collected from induced movement of particles sprayed on the surface or patterns shone on the surface of the sclera. Each has value, though any of the in vitro models are carried out under less than natural conditions of temperature, humidity and partial constraint of movement of some portion of the globe. Some models have assumed uniform scleral thickness or ignored thickness altogether, while others have assumed local isotropy ${ }^{71}$ or attempted to include the more likely situation of anisotropy ${ }^{72}$. In fact, recent human testing suggests significant anisotropy in human sclera ${ }^{73}$.

Comparisons of the stress-strain relationship of regions of the sclera in mouse, monkey and human eyes agree that the greatest strain is in the peripapillary zone adjacent to the $\mathrm{ONH}^{24,62}$. Other regional differences, such as those between nasal/temporal or superior/ inferior regions may differ among individual humans or by species.

\section{Scleral response to IOP-induced stress in experimental mouse glaucoma}

We have produced experimental glaucoma model in several strains of mice correlating the relative susceptibility to RGC loss with the findings in the sclera, including macroscopic and microscopic change, proteomic analysis, and biomechanical behavior. In this model, consistent IOP is produced by obstruction of aqueous humor outflow by injecting a mixture 
of 6 and $1 \mu \mathrm{m}$ polystyrene beads and viscoelastic into the anterior chamber (Figure 12$)^{74}$, causing axial globe enlargement and selective RGC loss (Figure 13). The method is based on an approach suggested by Sappington et al. ${ }^{75}$ We have identified differences among strains or genetic types of mice in susceptibility to RGC damage and have studied how the differences in scleral structure or response to glaucoma could be related to susceptibility. Our initial hypotheses included the rather simplistic idea that mice with bigger eyes would be more susceptible to glaucoma, as are axially myopic humans.

We identified that the albino CD1 strain was more susceptible to RGC loss than the B6 strain and that the DBA/2 strain is intermediate in sensitivity ${ }^{76}$. One mouse strain with an induced mutation in collagen $8 a 2$, a strain called $A c a 23$, in which the eye was longer than controls, was found to be less susceptible to glaucoma damage than its wild type B6 base strain (Figure 14) ${ }^{77}$. With extended IOP elevation in this model, there is an increase in axial length and width (6\% in CD1 and 10\% in B6). While the peripapillary sclera became thinner in both $\mathrm{CD} 1$ and B6 with glaucoma, most of the sclera uniformly thinned in CD1, but actually thickened in B6. Testing of the inflation of enucleated mouse eyes in a mechanical apparatus showed that the peripapillary sclera in CD1 controls had significantly greater meridional strain than B6 and had differences in the ratios of meridional to circumferential strain from B6 mice-i.e. the CD1 mice exhibited anisotropy of the inflation response. In both $\mathrm{CD} 1$ and $\mathrm{B} 6$ mice, exposure to chronic IOP elevation resulted in stiffer pressure-strain responses. While collagen 8 mutant (Aca23) mice had larger eyes than B6 controls, unlike the CD1, their inflation responses were stiffer than B6. Furthermore, they lost very few RGC at IOP exposures that damaged significant RGC in wild type B6 littermates (Figure 14). These findings suggest that large eye size alone is not the most important factor in glaucoma susceptibility in mice. Rather, a compliant baseline stress-strain response, anisotropy of mechanical response, and scleral thinning with chronic glaucoma were features associated with greater damage. The uniformly increased scleral stiffness after glaucoma exposure in mice mimics findings in monkey ${ }^{62,63}$ and human glaucoma eyes ${ }^{78}$.

\section{Microstructure of connective tissue}

We have studied the microstructure of sclera by combining measurements of the diffusion rates of fluorescently-labeled dextran molecules of various diameters with obstruction scaling models ${ }^{79}$ in collaboration with Hopkins colleague Justin Hanes. This permits evaluation of tissue microstructure that is not easily measured by classical fluid mechanics or elasticity measurement ${ }^{80}$. It is known that increased cross-linking (as envisioned here as a therapy) can alter corneal and scleral permeability ${ }^{81}$. Since tiny, $20 \mathrm{~nm}$ nanoparticles do not penetrate mouse or rat sclera ${ }^{82}$, we characterized diffusion of fluorescently-labeled dextrans of 20,000—70,000 molecular weight, using fluorescence recovery after photobleaching. Small regions were bleached during confocal microscopy and the re-entry of unbleached dextran from the periphery was measured quantitatively to estimate diffusivity. Initial studies have shown that the peripapillary sclera has lower diffusivity than the mid-sclera, and that the CD1 mice have greater diffusivity than do B6 mice (Figure 15).

\section{Proteomic changes}

With co-investigator Gulgun Tezel, we have conducted the first proteomic studies ${ }^{83}$ that compare sclera in normal and glaucoma mice. Both normal aging, diseases such as diabetes, and chemical treatment can increase glycation cross-linking, altering the structure and mechanics of collagen-containing matrices ${ }^{84}$, specifically increasing fibril diameter ${ }^{85,86}$ and increasing stiffness ${ }^{87,88}$. Our initial studies show that in both CD1 and B6 mice the exposure of sclera to chronic IOP elevation leads to significant increases in molecules that are important in maintenance and remodeling of the sclera. These include thrombospondins 1 and 4, several myosin species, fibromodulin, and heparin sulfate proteoglycan. The 
Ingenuity analysis of proteomic data suggested that there was upregulation in canonical pathways for integrin-linked kinase signaling and actin microskeleton signaling.

\section{Scleral cell responses}

The proteomic findings suggested that changes were occurring in the sclera quickly after IOP elevation, including features that indicated substantial change in activity of scleral fibroblasts. To investigate cellular changes, we have developed methods for study of the whole sclera and its regions by confocal microscopy. The fibroblasts of the sclera make up about $15 \%$ by volume of its thickness in histological measurements. With exposure to elevated IOP, we find that there is no significant change in the thickness or general orientation of scleral fibrillary elements or lamellae. Instead, it is the cell layers that expand. Cell division was quantified by standard Ki67 labeling and found to increase in glaucoma sclera, and to be greater in the B6 strain that was less sensitive to glaucoma damage to RGC. Furthermore, labeling for a-smooth muscle actin was dramatically increased in glaucoma sclera (Figure 16). This anatomical evidence is consistent with the initial proteomic data, indicating a transition to the myofibroblast phenotype among scleral cells. The important role of transition to myofibroblasts in the scleral response to experimental myopia in animals has been noted ${ }^{89,90}$. Thus, it is likely that therapeutic targets to alter susceptibility to glaucoma damage may exist in pathways related to scleral remodeling.

\section{Potential treatments for glaucoma that target the sclera}

The evidence cited here points to the high likelihood that the susceptibility to the effects of IOP in glaucoma could be altered by treatments that change the properties or responses of the sclera. We have previously suggested this approach and it is mentioned in recent reviews ${ }^{91}$. These could fall into two main areas: 1) change in the baseline state of the sclera so that its mechanical response to IOP is more favorable; and 2) favorable changes in the cell-based, biochemical processes of the sclera, as it responds to IOP. We cannot yet propose specific therapies, since the evidence does not fully support a direction for treatment. Rather, the review intends to support the need for research into these areas of potential therapy.

The mouse data suggest that eyes with mechanical responses that can be categorized as "stiffer" may be less susceptible to glaucoma damage. The characterization of behavior as "stiff" is an oversimplification. There are short-term and longer-term responses, regional responses in zones of sclera, and, for any given zone, anisotropy can be the case. Any specification of the features of a connective tissue is heavily dependent upon the conditions under which the tissue was tested. However, if we were to find after further research that eyes with a generally steeper stress-strain relation were less likely to suffer injury at a given IOP, then treatments that alter the sclera in that direction would be beneficial. Increased cross-linking of the cornea in keratoconus through use of riboflavin activated by ultraviolet light is being actively tested in humans ${ }^{92}$, and can alter stress-strain behavior, without significant damage to retina or other ocular structures ${ }^{93}$. Use of this or a similar approach for glaucoma was first suggested to the author by Stephen Trokel, Columbia University. Application of an agent that would increase cross-linking of key molecules in the sclera could be accomplished with chemicals that do not require activation by ultraviolet light. These could be delivered by subconjunctival injection in an outpatient setting. Theoretically, one treatment could accomplish the alteration of the stress-strain response of an eye to IOP, permanently reducing glaucoma susceptibility.

The positive effects of increased scleral cross-linking of fibrillar elements may be mitigated by several factors. First, we are not at present certain that making the sclera "stiffer" would be clearly beneficial in human eyes. Further animal research is needed to show that proposed methods for altering the sclera would provide protection in mouse and other animal models. 
It has been proposed that reducing the strain in the peripapillary sclera, instead of protecting the eye, would lead to a rigid perimeter for the optic nerve head, potentially intensifying the translaminar pressure gradient, and making the eye less safe. Second, the methods to alter sclera must be shown to avoid off-target effects that counteract their benefit. For example, the cross-linking treatment could adversely impact the major ocular blood vessels that traverse the sclera or the extraocular muscles. Third, the precise degree of cross-linking needed may vary from person to person, requiring a method to estimate the extent of treatment, or multiple small treatments. It would be very beneficial in any case to have methods that estimate the mechanical state of the sclera in the living eye. These could use imaging technology with induced perturbations in IOP.

It may be that a beneficial effect on sclera would be achieved not by stiffening, but by producing a less stiff or a more elastic response. In that case, agents that affect collagens or non-collagenous elements in this direction would be sought. These could include enzymatic digestion with collagenase, elastase, chondroitinase, or hyaluronidase. Weinreb has suggested that scleral properties may be altered by existing topical prostaglandin eye drop treatment for glaucoma ${ }^{94}$. Again, secondary detrimental effects and degree of treatment would need to be assessed. Treatment with prostaglandin increases sclera permeability, improving uveoscleral outflow, but with as yet unknown effects on mechanical behavior.

The second area for potential treatment is to alter the biochemical pathways that modulate the state of the sclera, most probably through acting on scleral fibroblasts. One example of such an approach has been taken with the Marfan syndrome. In Marfan syndrome, the mutated site in fibrillin-1 produces its disruption of connective tissue by activating transforming growth factor $\beta$ (TGF $\beta)^{95,96}$, with consequent abnormalities in connective tissues, leading to aortic dissection, ocular lens dislocation, and high myopia. Both gene expression and protein levels of TGF $\beta$ are elevated in OAG eyes in their human trabecular meshwork ${ }^{97}$ and $\mathrm{ONH}^{98,99,100,101}$. Our initial proteomic analyses in mouse glaucoma show $>2$-fold increase in thrombospondin 1 and 4 , which are activators of TGF $\beta$. A TGF $\beta$ antagonist, losartan, reduces active TGF $\beta$ levels in a mouse model of Marfan syndrome, reversing the clinical abnormality of the aorta ${ }^{102,103}$. TGF $\beta$ is involved in scleral remodeling in experimental myopia in tree shrews ${ }^{104}$. Abnormal activation/inhibition of TGF $\beta$ in the sclera and ONH could increase susceptibility to IOP-induced stress and potentiate OAG damage. It is feasible that a treatment of this type may act as a beneficial modulator of the scleral response in glaucoma; however, further investigation needs to be completed to understand which subtypes of TGF $\beta$ are pertinent in glaucoma, specifically in the locations of interest; the anterior eye, sclera, and optic nerve head. The pathways for change in the sclera require considerably more study before this can be advocated.

If we are to develop an approach to modulation of scleral response to IOP in glaucoma, a mode of delivery of the treatment would need to be developed as well. For agents that are to alter the basic structure of extracellular sclera, direct application to the sclera would be the obvious choice. This could be by aqueous solutions applied subconjunctivally into the orbit. If prolonged effect is needed, longer acting delivery methods by this route might include the drug encapsulated in nanoparticles. For agents that could pass through the conjunctiva, local eye drop application or sustained release from depot devices in the lacrimal canaliculus could be considered. However, it is unlikely that we would wish to expose the cornea to agents that could potentially be toxic to it, or reduce its clarity. Systemic delivery (such as through losartan pills) is feasible, but may have general body side effects that are undesirable. 


\section{Conclusion}

A new therapeutic approach to glaucoma is proposed that is based on reduction in IOPgenerated stress at the $\mathrm{ONH}$ by alteration of the sclera. This treatment would aim to block initial injury to RGC axons at an earlier stage of RGC dysfunction than past proposed neuroprotective treatments. In determining which connective tissue molecules and their metabolism are most likely to be important in causing or preventing glaucoma injury, this research area will direct the search for candidate genes related to glaucoma damage and myopia.

\section{Acknowledgments}

The authors thanks the members of his laboratory who contributed to the work presented here: Mary Ellen Pease, Ericka Oglesby, Matthew Steinhart, and Cathy Nguyen. Faculty collaborators who provided important expertise included Thao (Vicky) Nguyen, Baptiste Coudrillier, Keith Meek, Craig Boote, Justin Hanes, Gulgun Tezel, Don Zack, and Derek Welsbie.

\section{References}

1. Bengtsson B, Heijl A. Diurnal IOP fluctuation: not an independent risk factor for glaucomatous visual field loss in high-risk ocular hypertension. Graefe's Arch Clin Exper Ophthalmol. 2005; 243:513-8. [PubMed: 15756577]

2. Nouri-Mahdavi K, Hoffman D, Coleman A, Liu G, Li G, Gaasterland D, Caprioli J. Predictive factors for glaucomatous visual field progression in the Advanced Glaucoma Intervention Study. Ophthalmology. 2004; 111:1627-35. [PubMed: 15350314]

3. Morrison JC, Nylander KB, Lauer AK, Cepurna WO, Johnson E. Glaucoma drops control intraocular pressure and protect optic nerves in a rat model of glaucoma. Invest Ophthalmol Vis Sci. 1998; 39:526-31. [PubMed: 9501862]

4. Heijl A, Leske MC, Bengtsson B, Hyman L, Bengtsson B, Hussein M. the Early Manifest Glaucoma Trial Group . Reduction of intraocular pressure and glaucoma progression. Arch Ophthalmol. 2002; 120:1268-79. [PubMed: 12365904]

5. Kass MA, Heuer DK, Higginbotham EJ, Johnson CA, Keltner JL, Miller JP, Parrish RK 2nd, Wilson MR, Gordon MO. The Ocular Hypertension Treatment Study: a randomized trial determines that topical ocular hypotensive medication delays or prevents the onset of primary open-angle glaucoma. Arch Ophthalmol. 2002; 120:701-13. [PubMed: 12049574]

6. Martin KRG, Quigley HA, Zack DJ, Levkovitch-Verbin H, Kielczewski J, Valenta D, Baumrind L, Pease ME, Klein RL, Hauswirth WW. Gene therapy with brain-derived neurotrophic factor protects retinal ganglion cells in a rat glaucoma model. Invest Ophthalmol Vis Sci. 2003; 44:4357-65. [PubMed: 14507880]

7. McKinnon SJ, Lehman DM, Tahzib NG, Ransom NL, Reitsamer HA, Liston P, LaCasse E, Li Q, Korneluk RG, Hauswirth WW. Baculoviral IAP repeat-containing-4 protects optic nerve axons in a rat glaucoma model. Mol Ther. 2002; 5:780-7. [PubMed: 12027563]

8. Ji JZ, Elyaman W, Yip HK, Lee VW, Yick LW, Hugon J, So KF. CNTF promotes survival of retinal ganglion cells after induction of ocular hypertension in rats: the possible involvement of STAT3 pathway. Eur J Neurosci. 2004; 19:265-72. [PubMed: 14725620]

9. Huang W, Fileta JB, Dobberfuhl A, Filippopolous T, Guo Y, Kwon G, Grosskreutz CL. Calcineurin cleavage is triggered by elevated intraocular pressure, and calcineurin inhibition blocks retinal ganglion cell death in experimental glaucoma. Proc Natl Acad Sci U S A. 2005; 102:12242-7. [PubMed: 16103353]

10. Neufeld AH, Das S, Vora S, Gachie E, Kawai S, Manning PT, Connor JR. A prodrug of a selective inhibitor of inducible nitric oxide synthase is neuroprotective in the rat model of glaucoma. $\mathrm{J}$ Glaucoma. 2002; 11:221-5. [PubMed: 12140399]

11. Schwartz M. Neurodegeneration and neuroprotection in glaucoma: development of a therapeutic neuroprotective vaccine: the Friedenwald lecture. Invest Ophthalmol Vis Sci. 2003; 44:1407-11. [PubMed: 12657572] 
12. Nakazawa T, Nakazawa C, Matsubara A, Noda K, Hisatomi T, She H, Michaud N, HafeziMoghadam A, Miller JW, Benowitz LI. Tumor necrosis factor-alpha mediates oligodendrocyte death and delayed retinal ganglion cell loss in a mouse model of glaucoma. J Neurosci. 2006; 26:12633-41. [PubMed: 17151265]

13. Quigley HA, Hohman RM, Addicks EM, Massof RS, Green WR. Morphologic changes in the lamina cribrosa correlated with neural loss in open-angle glaucoma. Am J Ophthalmol. 1983; 95:673-91. [PubMed: 6846459]

14. Kerrigan LA, Zack DJ, Quigley HA, Smith SD, Pease ME. TUNEL-positive ganglion cells in human primary open angle glaucoma. Arch Ophthalmol. 1997; 115:1031-5. [PubMed: 9258226]

15. Quigley HA, Nickells RW, Kerrigan LA, Pease ME, Thibault DJ, Zack DJ. Retinal ganglion cell death in experimental glaucoma and after axotomy occurs by apoptosis. Invest Ophthalmol Vis Sci. 1995; 36:774-86. [PubMed: 7706025]

16. Quigley HA, Green WR. The histology of human glaucoma cupping and optic nerve damage: clinicopathologic correlation in 21 eyes. Ophthalmology. 1979; 10:1803-27. [PubMed: 553256]

17. Experimental glaucoma in the rhesus monkey. Invest Ophthalmol. 1974; 13:455-7. [PubMed: 4208801]

18. Quigley HA, Addicks EM, Green WR, Maumenee AE. Optic nerve damage in human glaucoma. II. The site of injury and susceptibility to damage. Arch Ophthalmol. 1981; 99:635-49. [PubMed: 6164357]

19. Quigley HA, Addicks EM. Regional differences in the structure of the lamina cribrosa and their relation to glaucomatous optic nerve damage. Arch Ophthalmol. 1981; 99:137-43. [PubMed: 7458737]

20. Boland MV, Quigley HA. Risk factors and open-angle glaucoma: concepts and applications. J Glaucoma. 2007; 16:406-18. [PubMed: 17571004]

21. Congdon NG, Broman AT, Bandeen-Roche K, Grover D, Quigley HA. Central corneal thickness and corneal hysteresis associated with glaucoma damage. Am J Ophthalmol. 2006; 141:868-75. [PubMed: 16527231]

22. Ebneter A, Wagels B, Zinkernagel MS. Non-invasive biometric assessment of ocular rigidity in glaucoma patients and controls. Eye. 2009; 23:606-611. [PubMed: 18309334]

23. Hommer A, Fuchsjager-Mayr G, Resch H, Vass C, Garhofer G, Schmetterer L. Estimation of ocular rigidity based on measurement of pulse amplitude using pneumotonometry and fundus pulse using laser interferometry in glaucoma. Invest Ophthalmol Vis Sci. 2008; 49:4046-4050. [PubMed: 18487379]

24. Coudrillier B, Tian J, Alexander S, Myers KM, Quigley HA, Nguyen TD. Biomechanics of the human posterior sclera: age- and glaucoma-related changes measured using inflation testing. Invest Ophthalmol Vis Sci. 2012; 53:1714-28. [PubMed: 22395883]

25. Tan JCH, Kalapesi FB, Coroneo MT. Mechanosensitivity and the eye: cells coping with the pressure. Br J Ophthalmol. 2006; 90:383-8. [PubMed: 16488967]

26. Grieshaber MC, Mozaffarieh M, Flammer J. What is the link between vascular dysregulation and glaucoma? Surv Ophthalmol. 2007; 52(Suppl 2):S144-54. [PubMed: 17998040]

27. Tezel G. Fourth ARVO/Pfizer Ophthalmics Research Institute Conference Working Group. The role of glia, mitochondria, and the immune system in glaucoma. Invest Ophthalmol Vis Sci. 2009; 50:1001-12. [PubMed: 19244206]

28. Yang H, Williams G, Downs JC, Sigal IA, Roberts MD, Thompson H, Burgoyne CF. Posterior (outward) migration of the lamina cribrosa and early cupping in monkey experimental glaucoma. Invest Ophthalmol Vis Sci. 2011; 52:7109-7121. [PubMed: 21715355]

29. Burgoyne CF, Downs JC, Bellezza AJ, Suh JK, Hart RT. The optic nerve head as a biomechanical structure: a new paradigm for understanding the role of IOP-related stress and strain in the pathophysiology of glaucomatous optic nerve head damage. Prog Retin Eye Res. 2005; 24:39-73. [PubMed: 15555526]

30. Sigal IA, Yang H, Roberts MD, Burgoyne CF, Downs JC. IOP-induced lamina cribrosa displacement and scleral canal expansion: an analysis of factor interactions using parameterized eye-specific models. Invest Ophthalmol Vis Sci. 2011; 52:1896-907. [PubMed: 20881292] 
31. Sigal IA, Flanagan JG, Ethier CR. Factors influencing optic nerve head biomechanics. Invest Ophthalmol Vis Sci. 2005; 46:4189-99. [PubMed: 16249498]

32. Girard MJA, Suh J-KF, Mottlang M, Burgoyne CF, Downs JC. Biomechanical changes in the sclera of monkey eyes exposed to chronic IOP elevations. Invest Ophthamol Vis Sci. 2011; 52:5656-5669.

33. Quigley HA, Broman A. The number of persons with glaucoma worldwide in 2010 and 2020. Br J Ophthalmol. 2006; 90:151-156.

34. Morrison JC, Dorman-Pease ME, Dunkelberger GR, Quigley HA. Optic nerve head extracellular matrix in primary optic atrophy and experimental glaucoma. Arch Ophthalmol. 1990; 108:1020-4. [PubMed: 2369339]

35. Morrison JC, Moore CG, Deppmeier LMH, Gold BF, Meshul CK, Johnson EC. A rat model of chronic pressure-induced optic nerve damage. Exp Eye Res. 1997; 64:85-96. [PubMed: 9093024]

36. Soto I, Pease ME, Son JL, Shi X, Quigley HA, Marsh-Armstrong N. Retinal ganglion cell loss in a rat ocular hypertension model is sectorial and involves early optic nerve axon loss. Invest Ophthalmol Vis Sci. 2011; 52:434-41. [PubMed: 20811062]

37. Wong AA, Brown RE. A neurobehavioral analysis of the prevention of visual impairment in the DBA/2J mouse model of glaucoma. Invest Ophthalmol Vis Sci. 2012; 53:5956-66. [PubMed: 22859742]

38. Sun D, Lye-Barthel M, Masland RH, Jakobs TC. The morphology and spatial arrangement of astrocytes in the optic nerve head of the mouse. J Comp Neurol. 2009; 516:1-19. [PubMed: 19562764]

39. Zhou J, Rappaport EF, Tobias JW, Young TL. Differential gene expression in mouse sclera during ocular development. Invest Ophthalmol Vis Sci. 2006; 47:1794-802. [PubMed: 16638983]

40. Olsen TW, Aaberg SY, Geroski DH, Edelhauser HF. Human sclera: thickness and surface area. Am J Ophthalmol. 1998; 125:237-41. [PubMed: 9467451]

41. Howell GR, Soto I, Zhu X, Ryan M, Macalinao DG, Sousa GL, Caddle LB, MacNicoll KH, Barbay JM, Porciatti V, Anderson MG, Smith RS, Clark AF, Libby RT, John SW. Radiation treatment inhibits monocyte entry into the optic nerve head and prevents neuronal damage in a mouse model of glaucoma. J Clin Invest. 2012; 122:1246-1261. [PubMed: 22426214]

42. John SW, Smith RS, Savinova OV, Hawes NL, Chang B, Turnbull D, Davisson M, Roderick TH, Heckenlively JR. Essential iris atrophy, pigment dispersion, and glaucoma in DBA/2J mice. Invest Ophthalmol Vis Sci. 1998; 39:951-962. [PubMed: 9579474]

43. Mabuchi F, Lindsey JD, Aihara M, Mackey MR, Weinreb RN. Optic nerve damage in mice with a targeted type I collagen mutation. Invest Ophthalmol Vis Sci. 2004; 45:1841-1845. [PubMed: 15161848]

44. Zhou Y, Grinchuk O, Tomarev SI. Transgenic mice expressing the Tyr437His mutant of human myocilin protein develop glaucoma. Invest Ophthalmol Vis Sci. 2008; 49:1932-1939. [PubMed: 18436825]

45. Mao M, Hedberg-Buenz A, Koehn D, John SWM, Anderson MG. Anterior segment dysgenesis and early-onset glaucoma in nee mice with mutation of Sh3pxd2b. Invest Ophthalmol Vis Sci. 2011; 52:2679-2688. [PubMed: 21282566]

46. McDowell CM, Luan T, Zhang Z, Putliwala T, Wordinger RJ, Millar JC, John SWM, Pang I-H, Clark AF. Mutant human myocilin induces strain specific differences in ocular hypertension and optic nerve damage in mice. Exper Eye Res. 2012; 100:65-72. [PubMed: 22575566]

47. Junglas B, Kuespert S, Seleem AA, Struller T, Ullmann S, Bösl M, Bosserhoff A, Köstler J, Wagner R, Tamm ER, Fuchshofer R. Connective tissue growth factor causes glaucoma by modifying the actin cytoskeleton of the trabecular meshwork. Am J Pathol. 2012; 180:2386-2403. [PubMed: 22542845]

48. Senatorov V, Malyuka I, Fariss R, Wawrousek EF, Swaminathan S, Sharan SK, Tomarev S. Expression of mutated mouse myocilin induces open- angle glaucoma in transgenic mice. $\mathrm{J}$ Neurosci. 2006; 26: 11903-11914. [PubMed: 17108164]

49. Hernandez MR, Andrzejewska WM, Neufeld AH. Changes in the extracellular matrix of the human optic nerve head in primary open-angle glaucoma. Am J Ophthalmol. 1990; 109:180-8. [PubMed: 2405683] 
50. Quigley HA, Dorman-Pease ME, Brown AE. Quantitative study of collagen and elastin of the optic nerve head and sclera in human and experimental monkey glaucoma. Curr Eye Res. 1991; 10:87788. [PubMed: 1790718]

51. Quigley HA, Hohman RM, Addicks EM, Massof RS, Green WR. Morphologic changes in the lamina cribrosa correlated with neural loss in open-angle glaucoma. Am J Ophthalmol. 1983; 95:673-91. [PubMed: 6846459]

52. Quigley HA, Brown A, Dorman-Pease ME. Alterations in elastin of the optic nerve head in human and experimental glaucoma. Br J Ophthalmol. 1991; 75:552-7. [PubMed: 1911659]

53. Yan D, McPheeters S, Johnson G, Utzinger U, Vande Geest JP. Microstructural differences in the human posterior sclera as a function of age and race. Invest Ophthalmol Vis Sci. 2011; 52:821829. [PubMed: 21051726]

54. Pijanka JK, Coudrillier B, Ziegler K, Sorensen T, Meek KM, Nguyen TD, Quigley HA, Boote C. Quantitative mapping of collagen fiber orientation in non-glaucoma and glaucoma posterior human scleras. Invest Ophthalmol Vis Sci. 2012; 53:5258-70. [PubMed: 22786908]

55. Clark SJ, Keenan TDL, Fielder HL, Collinson LJ, Holey RJ, Merry CL, van Kuppevelt TH, Day AJ, Bishop PN. Mapping the differential distribution of glycosaminoglycans in the adult human retina, choroid, and sclera. Invest Ophthalmol Vis Sci. 2011; 52:6511-6521. [PubMed: 21746802]

56. Hernandez MR. Ultrastructural immunocytochemical analysis of elastin in the human lamina cribrosa. Changes in elastic fibers in primary open-angle glaucoma. Invest Ophthalmol Vis Sci. 1992; 33:2891-2903. [PubMed: 1526740]

57. Quigley HA, Pease ME, Thibault D. Change in the appearance of elastin in the lamina cribrosa of glaucomatous optic nerve heads. Graefe's Arch Clin Exp Ophthalmol. 1994; 232:257-61. [PubMed: 8045433]

58. Yang H, Williams G, Downs JC, Sigal IA, Roberts MD, Thompson H, Burgoyne CF. Posterior (Outward) Migration of the Lamina Cribrosa and Early Cupping in Monkey Experimental Glaucoma. Ivest Opthalmol Vis Sci. 2011; 52:7109-7121.

59. Olsen TW, Edelhauser HF, Lim JI, Geroski DH. Human scleral permeability. Effects of age, cryotherapy, transscleral diode laser, and surgical thinning. Invest Ophthalmol Vis Sci. 1995; 36:1893-1903. [PubMed: 7543465]

60. Urban Z, Agapova O, Hucthagowder V, Yang P, Starcher BC, Hernandez MR. Population differences in elastin matauration in optic nerve head tissue and astrocytes. Invest Ophthalmol Vis Sci. 2007; 48:3209-15. [PubMed: 17591890]

61. Thorleifsson G, Magnusson KP, Sulem P, Walters GB, Gudbjartsson DF, Stefansson H, Jonsson T, Jonasdottir A, Jonasdottir A, Stefansdottir G, Masson G, Hardarson GA, Petursson H, Arnarsson A, Motallebipour M, Wallerman O, Wadelius C, Gulcher JR, Thorsteinsdottir U, Kong A, Jonasson F, Stefansson K. Common sequence variants in the LOXL1 gene confer susceptibility to exfoliation glaucoma. Science. 2007; 317:1397-1400. [PubMed: 17690259]

62. Gottanka J, Flugel-Koch C, Martus P, Johnson DH, Lütjen-Drecoll E. Correlation of pseudoexfoliative material and optic nerve damage in pseudoexfoliation syndrome. Invest Ophthalmol Vis Sci. 1997; 38:2435-2446. [PubMed: 9375560]

63. Downs JC, Suh J-KF, Thomas KA, Bellezza AJ, Hart RT, Burgoyne CF. Viscoelastic material properties of the peripapillary sclera in normal and early-glaucoma monkey eyes. Invest Ophthalmol Vis Sci. 2005; 46:540-6. [PubMed: 15671280]

64. Woo SL, Kobayashi AS, Schlegel WA, Lawrence C. Nonlinear material properties of intact cornea and sclera. Exp Eye Res. 1972; 14:29-39. [PubMed: 5039845]

65. Spoerl E, Boehm AG, Pillunat LE. The influence of various substances on the biomechanical behavior of lamina cribrosa and peripapillary sclera. Invest Ophthalmol Vis Sci. 2005; 46:128690. [PubMed: 15790892]

66. Myers KM, Cone FE, Quigley HA, Gelman SE, Pease ME, Nguyen TD. The in vitro inflation response of mouse sclera. Exp Eye Res. 2010; 91:866-75. [PubMed: 20868685]

67. Phillips JR, Khalaj M, McBrien NA. Induced myopia associated with increased scleral creep in the chick and tree shrew eyes. Invest Ophthalmol Vis Sci. 2000; 41:2028-34. [PubMed: 10892839]

68. Downs JC, Yang H, Girkin C, Sakata L, Bellezza A, Thompson H, Burgoyne CF. Threedimensional histomorphometry of the normal and early glaucomatous monkey optic nerve head: 
Neural canal and subarachnoid space architecture. Invest Ophthalmol Vis Sci. 2007; 48:3195-208. [PubMed: 17591889]

69. Girard MJ, Suh JK, Bottlang M, Burgoyne CF, Downs JC. Biomechanical changes in the sclera of monkey eyes exposed to chronic IOP elevations. Invest Ophthalmol Vis Sci. 2011; 52:5656-5669. [PubMed: 21519033]

70. Girard MJ, Suh JK, Bottlang M, Burgoyne CF, Downs JC. Scleral biomechanics in the aging monkey eye. Invest Ophthalmol Vis Sci. 2009; 50:5226-37. [PubMed: 19494203]

71. Boyce BL, Jones RE, Nguyen TD, Grazier JM. Stress-controlled viscoelastic tensile response of bovine cornea. J Biomech. 2007; 40:2367-76. [PubMed: 17240381]

72. Lanir Y. Constitutive Equations for Fibrous Connective Tissues. J Biomech. 1983; 16:1-12. [PubMed: 6833305]

73. Coudrillier, B.; Boote, C.; Quigley, HA.; Nguyen, TD. Scleral anisotropy and its effects on the optic nerve head deformation with intraocular pressure. In preparation

74. Cone FE, Steinhart MR, Oglesby EN, Kalesnykas G, Pease ME, Quigley HA. The effects of anesthesia, mouse strain and age on intraocular pressure and an improved murine model of experimental glaucoma. Exp Eye Res. 2012; 99:27-35. [PubMed: 22554836]

75. Sappington RM, Carlson BJ, Crish SD, Calkins D. The microbead occlusion model: A paradigm for induced ocular hypertension in rats and mice. Invest Ophthalmol Vis Sci. 2010; 51: 207-216. [PubMed: 19850836]

76. Cone FE, Gelman SE, Son JL, Pease ME, Quigley HA. Differential susceptibility to experimental glaucoma among 3 mouse strains using bead and viscoelastic injection. Exp Eye Res. 2010; 91:415-24. [PubMed: 20599961]

77. Steinhart MR, Cone FE, Nguyen C, Nguyen TD, Pease ME, Puk O, Graw J, Oglesby E, Quigley HA. Mice with an induced mutation in Collagen 8A2 develop larger eyes and are resistant to retinal ganglion cell damage in an experimental glaucoma model. Mol Vis. 2012; 18:1093-106. [PubMed: 22701298]

78. Nguyen C, Cone FE, Nguyen TD, Coudrillier B, Pease ME, Steinhart MR, Oglesby EN, Quigley HA. Studies of scleral biomechanical behavior related to susceptibility for retinal ganglion cell loss in experimental mouse glaucoma. Invest Ophthalmol Vis Sci. 2012 Accepted January 7th. Epub only.

79. Danysh BP, Patel TP, Czymmek KJ, Edwards DA, Wang L, Pande J, Duncan MK. Characterizing molecular diffusion in the lens capsule. Matrix Biology. 2010; 29:228-236. [PubMed: 20026402]

80. Suh J, Dawson M, Hanes J. Real-time multiple-particle tracking: applications to drug and gene delivery. Adv Drug Deliv Rev. 2005; 57:63-78. [PubMed: 15518921]

81. Stewart JM, Schultz DS, Lee O-T, Trinidad ML. Collagen cross-links reduce corneal permeability. Invest Ophthalmol Vis Sci. 2009; 50:1606-1612. [PubMed: 19060268]

82. Amrite AC, Edelhauser HF, Singh SR, Kompella UB. Effect of circulation on the disposition and ocular tissue distribution of $20 \mathrm{~nm}$ nanoparticles after periocular administration. Molecular Vision. 2008; 14:150-160. [PubMed: 18334929]

83. Tezel G, Yang X, Cai J. Proteomic identification of oxidatively modified retinal proteins in a chronic pressure-induced rat model of glaucoma. Invest Ophthalmol Vis Sci. 2005; 46:3177-87. [PubMed: 16123417]

84. Tanaka S, Avigad G, Brodsky B, Eikenberry EF. Glycation induces expansion of the molecular packing of collagen. J Mol Biol. 1988; 203:495-505. [PubMed: 3143838]

85. Brummer G, Littlechild S, McCall S, Zhang Y, Conrad GW. The role of non-enzymatic glycation and carbonyls in collagen cross-linking for the treatment of keratoconus. Invest Ophthalmol Vis Sci. EPub July 1, 2011.

86. Malik NS, Moss SJ, Ahmed N, Furth AJ, Wall RS, Meek KM. Ageing of the human corneal stroma: structural and biochemical changes. Biochim Biophys Acta. 1992; 1138:222-8. [PubMed: 1547284]

87. Schultz DS, Lotz JC, Lee SM, Trinidad ML, Stewart JM. Structural factors that mediate scleral stiffness. Invest Ophthalmol Vis Sci. 2008; 49:4232-4236. [PubMed: 18539943] 
88. Hansen P, Hassenkam T, Svensson RB, Aagaard P, Trappe T, Haraldsson BT, Kjaer M, Magnusson P. Glutaraldehyde cross-linking of tendon-mechanical effects at the level of the tendon fascicle and fibril. Conn Tiss Res. 2009; 50:211-222.

89. McBrien NA, Jobling AI, Gentle A. Biomechanics of the sclera in myopia: Extracellular and cellular factors. Optom Vis Sci. 2009; 86:E23-E30. [PubMed: 19104466]

90. Summers Rada JA, Shelton S, Norton TT. The sclera and myopia. Experimental Eye Research. 2006; 82:185-200. [PubMed: 16202407]

91. Strouthidis NG, Girard MJA. Altering the way the optic nerve head responds to intraocular pressure - a potential approach to glaucoma therapy. Curr Opin Pharmacol. 2012 Sep 19. pii: S1471-4892(12)00158-0. [Epub ahead of print]. 10.1016/j.coph.2012.09.001

92. Wollensak G, Spoerl E, Seiler T. Riboflavin/ultraviolet-A-induced collagen crosslinking for the treatment of keratoconus. Am J Ophthalmol. 2003; 135:620-627. [PubMed: 12719068]

93. Wollensak G, Iomdina E. Crosslinking of scleral collagen in the rabbit using glyceraldehydes. J Cataract Refract Surg. 2008; 34:651-656. [PubMed: 18361989]

94. Weinreb RN. Enhancement of scleral macromolecular permeability with prostaglandins. Trans Am Ophthalmol Soc. 2001; 99:319-343. [PubMed: 11797317]

95. Neptune ER, Frischmeyer PA, Arking DE, Myers L, Bunton TE, Gayraud B, Ramirez F, Sakai LY, Dietz HC. Dysregulation of TGF-beta activation contributes to pathogenesis in Marfan syndrome. Nat Genet. 2003; 33:407-11. [PubMed: 12598898]

96. Ng CM, Cheng A, Myers LA, Martinez-Murillo F, Jie C, Bedja D, Gabrielson KL, Hausladen JM, Mecham RP, Judge DP, Dietz HC. TGF-beta-dependent pathogenesis of mitral valve prolapse in a mouse model of Marfan syndrome. J Clin Invest. 2004; 114:1586-92. [PubMed: 15546004]

97. Sethi A, Mao W, Wordinger RJ, Clark AF. Transforming growth factor $-\beta$ induces extracellular matrix protein cross-linking lysyl oxidase (LOX) genes in human trabecular meshwork cells. Invest Ophthalmol Vis Sci. 2011; 52:5240-5250. [PubMed: 21546528]

98. Johnson EC, Cepurna WO, Doser TA, Morrison JC. Global changes in optic nerve head gene expression after exposure to elevated intraocular pressure in a rat glaucoma model. Invest Ophthalmol Vis Sci. 2007; 48:3161-77. [PubMed: 17591886]

99. Pena JDO, Taylor AW, Ricard CS, Vidal I, Hernandez MR. Transforming growth factor isoforms in human optic nerve heads. Br J Ophthalmol. 1999; 83:209-18. [PubMed: 10396201]

100. Zode GS, Sethi A, Brun-Zinkernagel A-M, Chang I-F, Clark AF, Wordinger RJ. Transforming growth factor- $\beta 2$ increases extracellular matrix proteins in optic nerve head cells via activation of the Smad signaling pathway. Mol Vis. 2011; 17:1745-58. [PubMed: 21738403]

101. Kirwan RP, Wordinger RJ, Clark AF, O'Brien CJ. Differential global and extra-cellular matrix focused gene expression patterns between normal and glaucomatous human lamina cribrosa cells. Mol Vis. 2009; 15:76-88. [PubMed: 19145252]

102. Habashi JP, Judge DP, Holm TM, Cohn RD, Loeys BL, Cooper TK, Myers L, Klein EC, Liu G, Calvi C, Podowski M, Neptune ER, Halushka MK, Bedja D, Gabrielson K, Rifkin DB, Carta L, Ramirez F, Huso DL, Dietz HC. Losartan, an AT1 antagonist, prevents aortic aneurysm in a mouse model of Marfan syndrome. Science. 2006; 312:117-21. [PubMed: 16601194]

103. Habashi JP, Doyle JJ, Holm TM, Aziz H, Schoenhoff F, Bedha D, Chen Y, Modiri AN, Judge DP, Dietz HC. Angiotensin II type 2 receptor signaling attenuates aortic aneurysm in mice through ERK antagonism. Science. 2011; 332:361-365. [PubMed: 21493863]

104. Jobling AL, Nguyen M, Gentle A, McBrien NA. Isoform specific changes in scleral transforming growth factor beta expression and the regulation of collagen synthesis during myopia progression. J Biol Chem. 2004; 30:18121-18126. [PubMed: 14752095] 

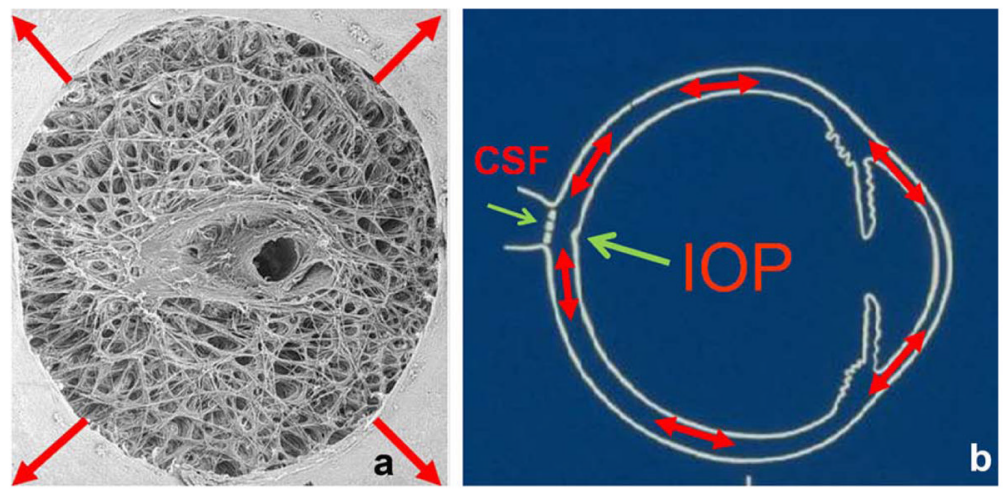

Fig. 1.

IOP- related stress in the eye wall. A) Scanning electron micrograph of human lamina cribrosa (optic nerve head) indicating the direction in which hoop stress acts on the structure (red arrows). B) Schematic image shows hoop stress (red arrows) in the sclera acting circumferentially, while the translaminar pressure difference between intraocular pressure (IOP) and cerebrospinal fluid pressure (CSF) expressed at the retrolaminar optic nerve oppose each other to develop a second direction of stress on the optic nerve head (green arrows). 


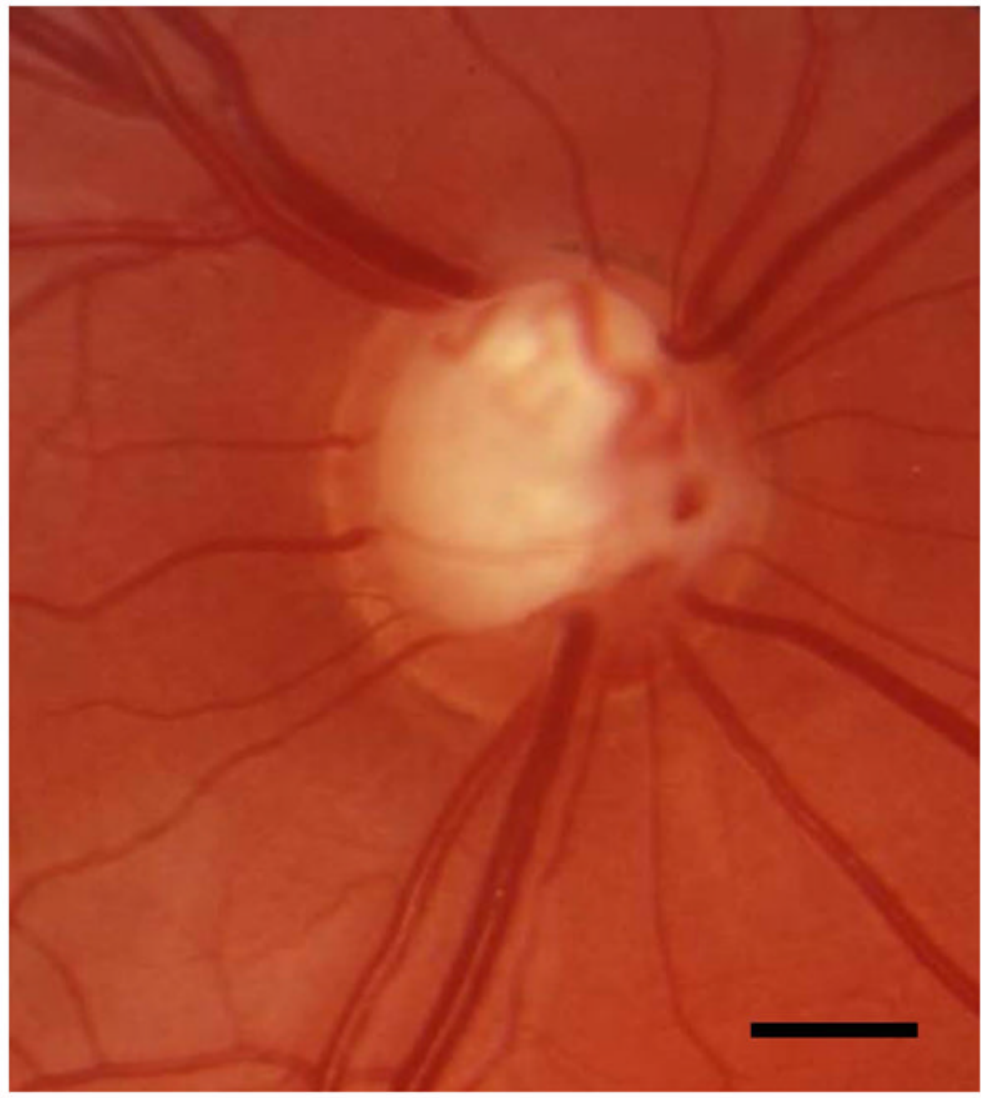

Fig. 2.

Fundus photograph from a glaucoma patient showing an increased cup to disc ratio and excavation or deepening of the optic nerve head. (scale bar $=1 \mathrm{~mm}$ ) 

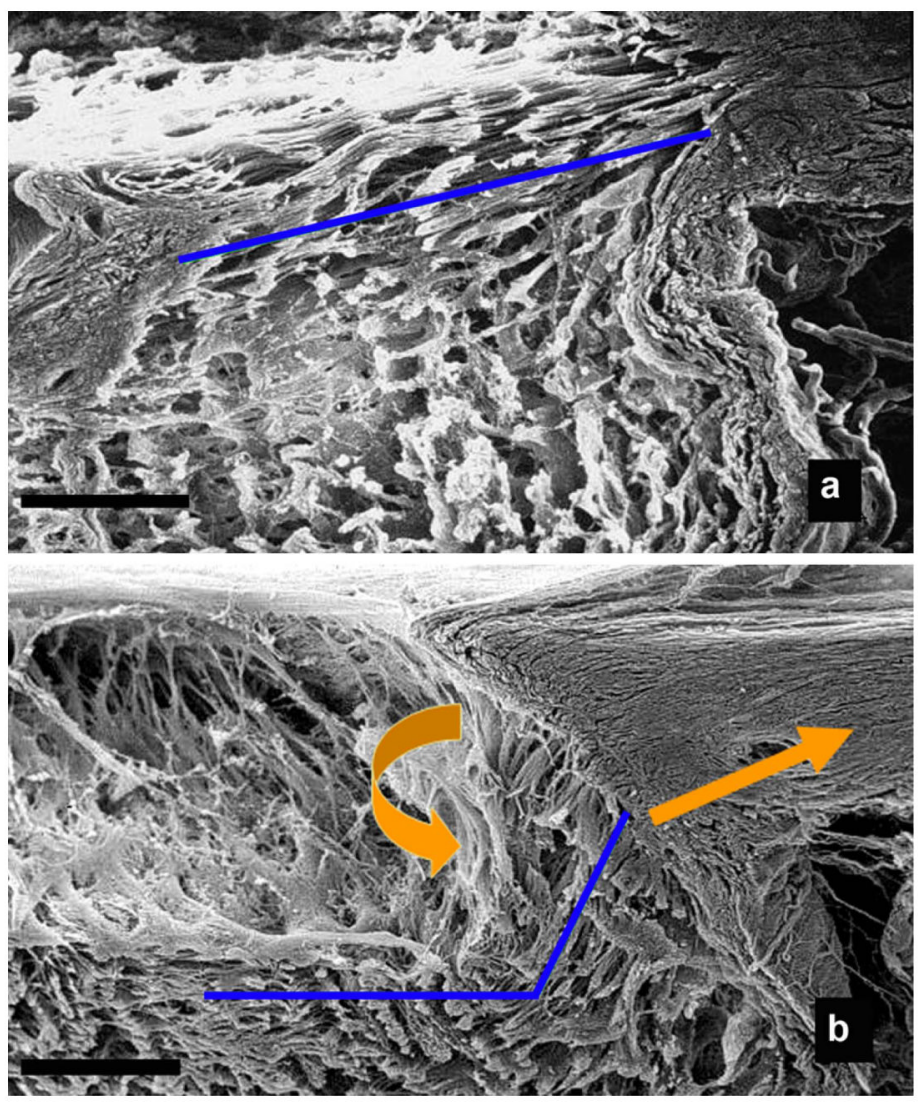

Fig. 3.

Scanning electron micrographs of the optic nerve head in human eyes. A) Normal eye has lamina cribrosa inserting into peripapillary sclera at modest angle. B) Glaucoma eye with excavation with expansion of scleral diameter and rotation of laminar insertion (orange arrows). Position of lamina is posterior and angulated relative to normal appearance (blue lines). (Scale bar $=100 \mu \mathrm{m})$ 


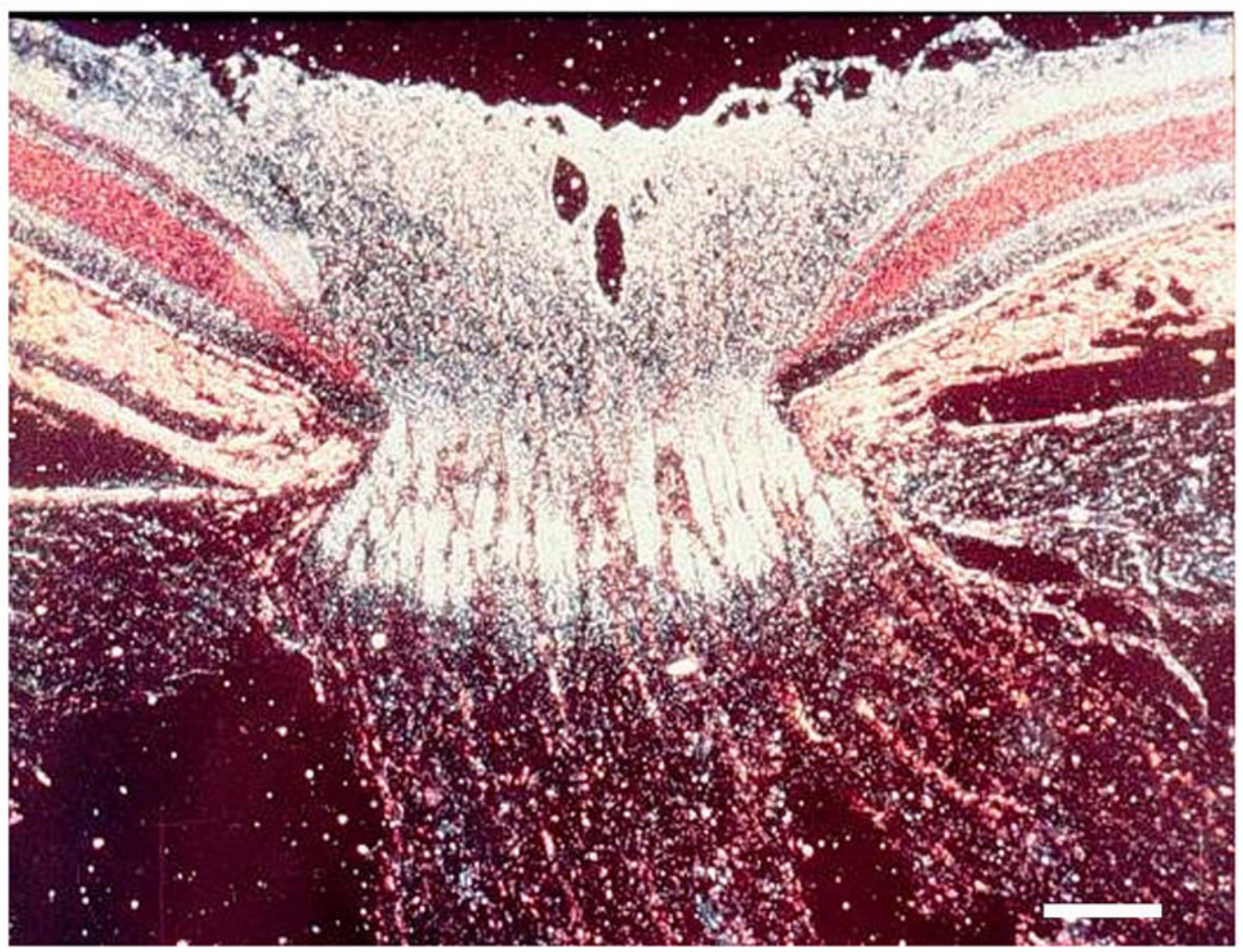

Fig. 4.

Glaucoma injury to RGC axons at the lamina cribrosa. Axonal transport blockade is demonstrated by the obstruction of radioactive protein movement by anterograde transport in experimental monkey glaucoma (white grains accumulated at lamina cribrosa). (Scale bar $=300 \mu \mathrm{m})$ 

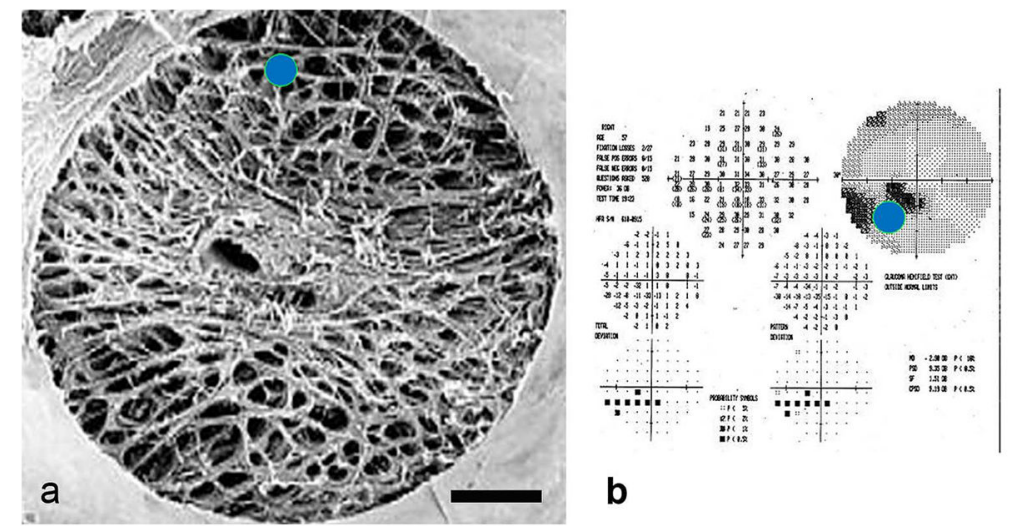

b

Fig. 5.

Lamina cribrosa in scanning electron micrograph shows: (A) the larger dark pores between connective tissue beams are larger in the superior (blue dot) and inferior optic nerve head, corresponding to the portion of the nerve head where axons pass through that subserve the position of most typical visual field loss in glaucoma (here, the lower nasal field zone (B). (Scale bar $=300 \mu \mathrm{m}$ ) 


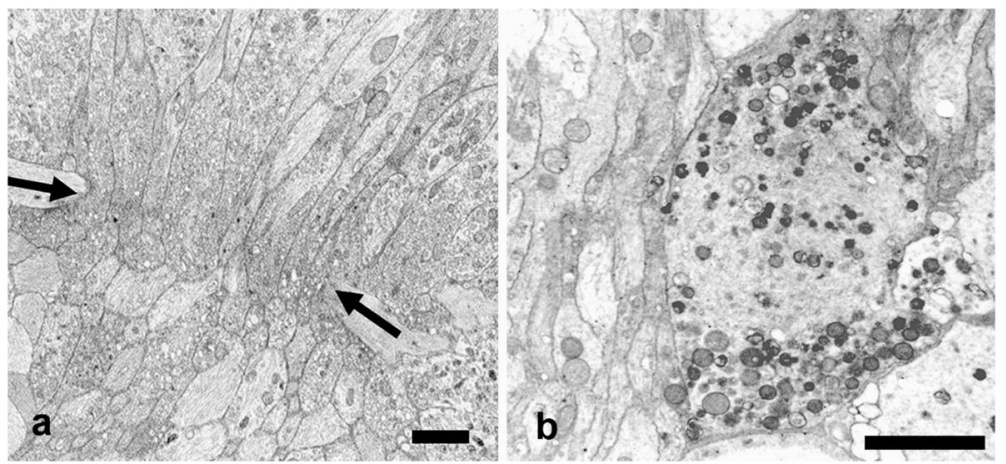

Fig. 6.

Axon transport obstruction in the optic nerve head. A) the obstruction of transport is shown by swelling of axons with organelles in a human eye with glaucoma; B) similar swelling of axons with organelles in an experimental mouse eye with chronic intraocular pressure elevation. (Scale bar $=500 \mathrm{~nm}$ ) 


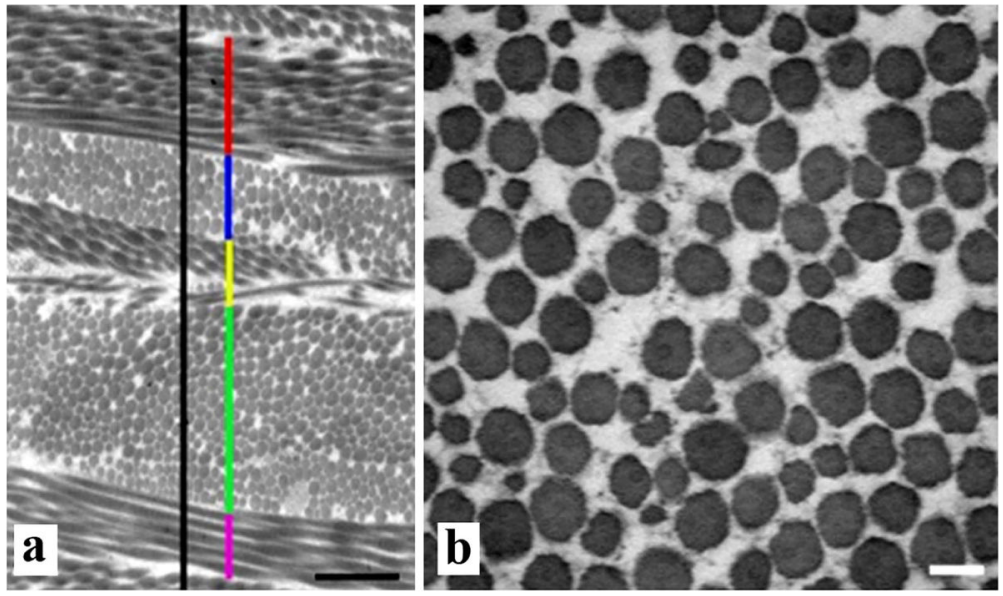

Fig. 7.

Transmission electron micrographs of CD1 mouse sclera tissue stained with tannic acid to intensify collagen fibrils. A) Quantification of height and orientation of collagen bundles in mid-sclera (color bars show thickness of sequential lamellae, bar = 1um); B) Collagen fibrils in cross-section. (Scale bar $=100 \mathrm{~nm})$ 
CD1- Control- Collagen Fiber Diamater Distribution

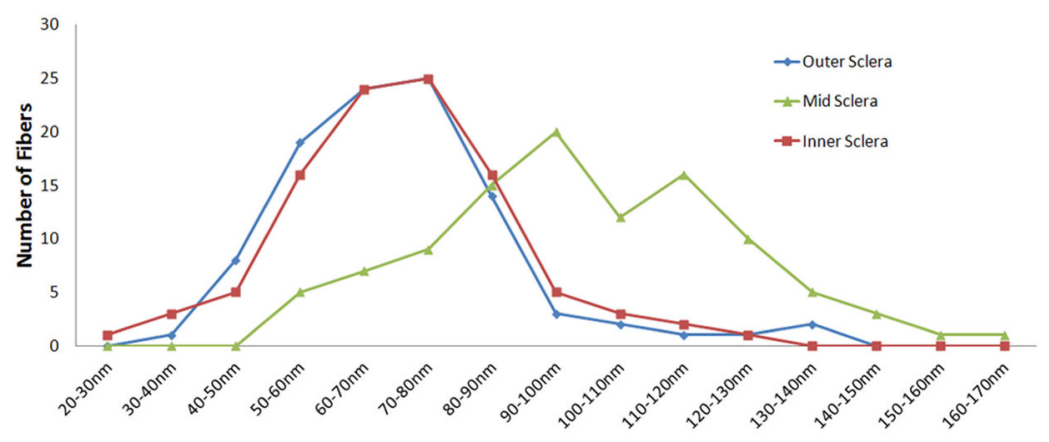

Fig. 8.

Graph shows CD1 mouse collagen fiber diameter distribution. Outer and inner sclera have similar number of fibers and diameter size, than the mid-sclera fibers. 


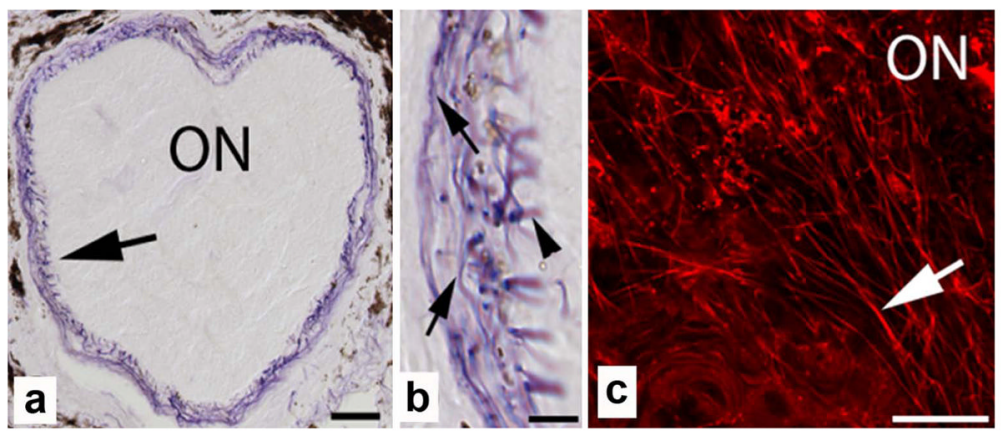

Fig. 9.

Elastin distribution in mouse peripapillary sclera. A) Normal mouse optic nerve (ON) head peripapillary region, with ring of elastin fibers (Luna stain; bar $=30 \mu \mathrm{m}$ ); (B) elastin circumferentially arranged at the ON (arrows), with arrowhead indicating elastin bridging to pia mater (bar=10 $\mu \mathrm{m})$. (C) Confocal immunolabelling of elastin (white arrow) in circumferential pattern at $\mathrm{ONH}($ Scale bar $=20 \mu \mathrm{m})$. 


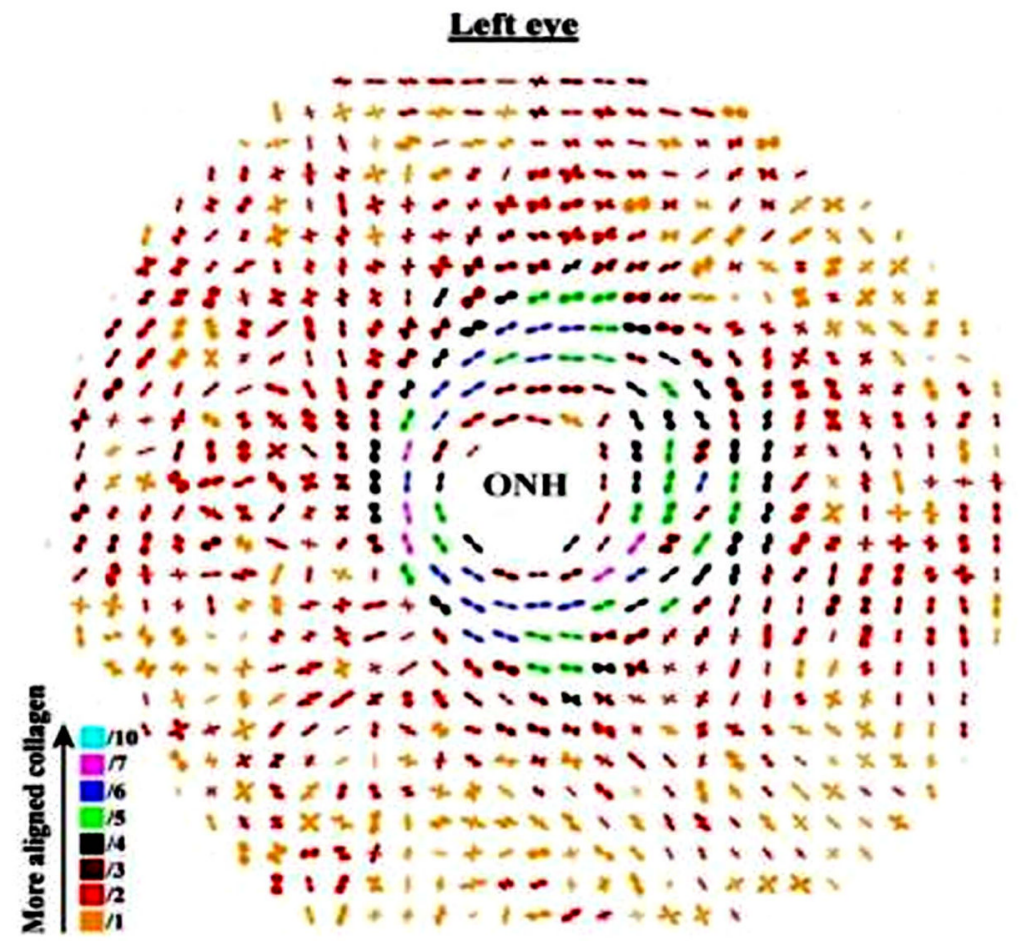

Fig. 10.

Wide-angle $x$-ray scattering data from human sclera, showing the orientation of fibers. The fibers are arranged in a circumferential pattern in the peripapillary sclera surrounding the optic nerve head (ONH). The different colors represent the magnitude of orientation. 

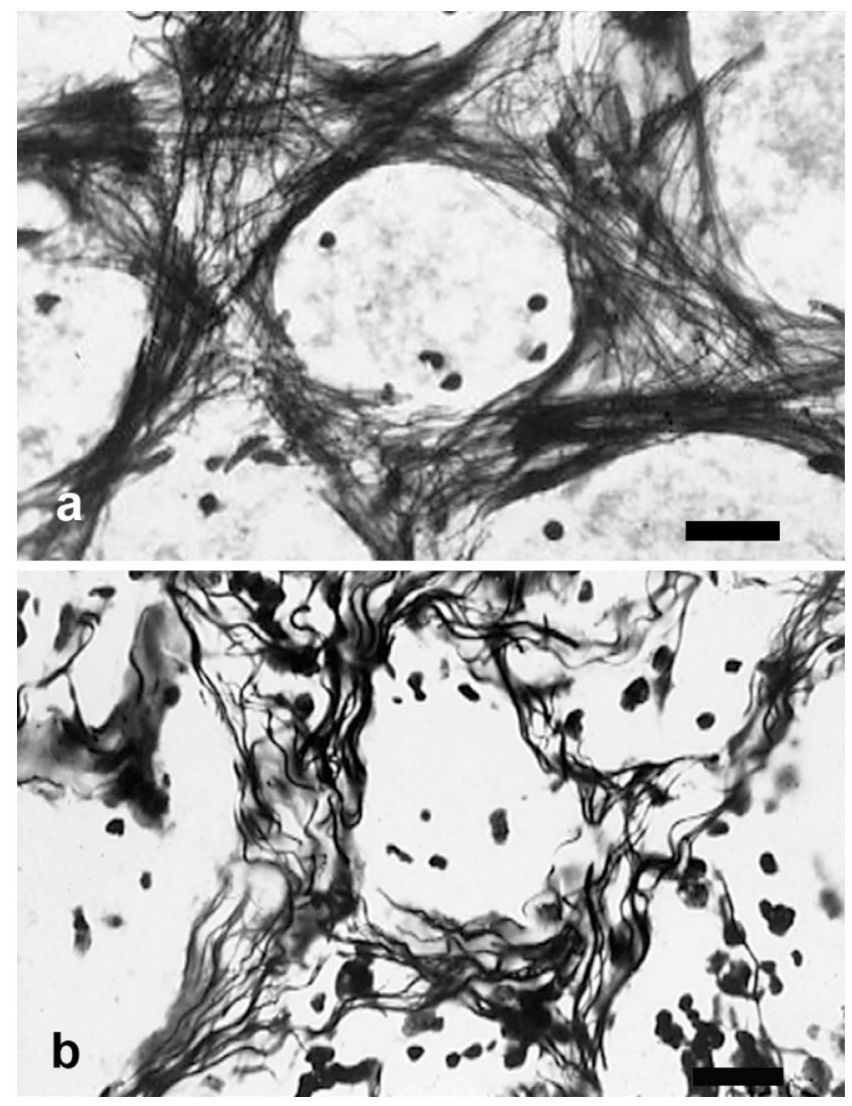

Fig. 11.

Elastin bundles in the human lamina cribrosa, Luna stain, light microscopy. A) Normal elastin in laminar beams is straight and aligned from one edge of lamina to the other. B) Glaucoma eye, shows elastin fibers are wavy in appearance, perhaps indicating disinsertion from connective tissue matrix as an effect of chronic damage. (Scale bar $=700 \mathrm{~nm}$ ) 


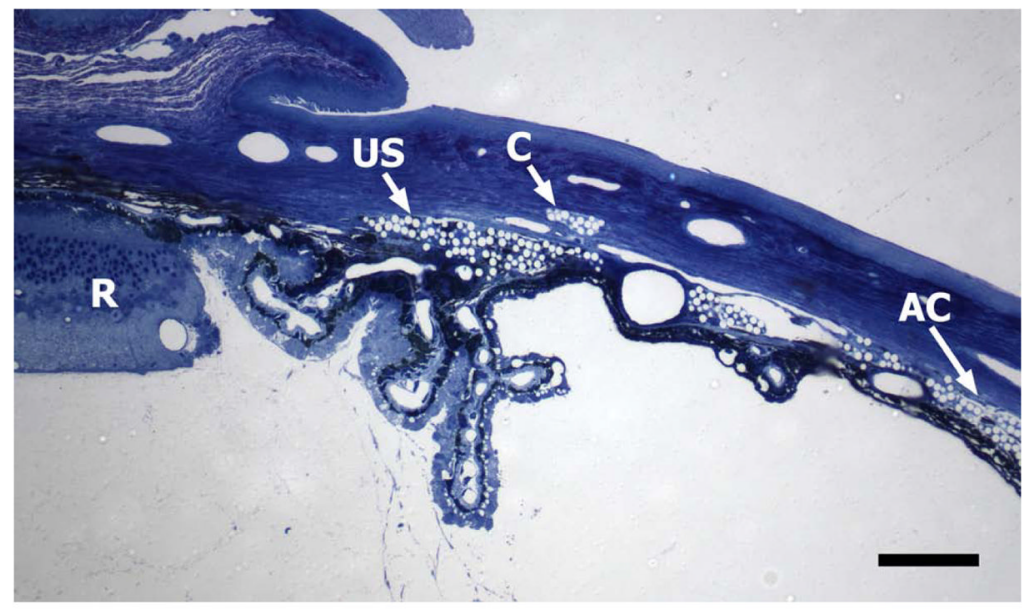

Fig. 12.

A: Anterior segment of control, non-injected, C57BL/6 younger mouse. B: Anterior segment of C57BL/6 younger mouse 6 weeks after bead injection. Beads are seen as clear spheres due to extraction of polystyrene during epoxy embedding. Beads are found in the iris stroma, in the uveoscleral pathway between ciliary body and sclera (US) and in outflow channels equivalent to Schlemm's canal (S). Anterior chamber (AC), Retina (R). (1\% toluidine blue; scale bars $=70 \mu \mathrm{m})$. 


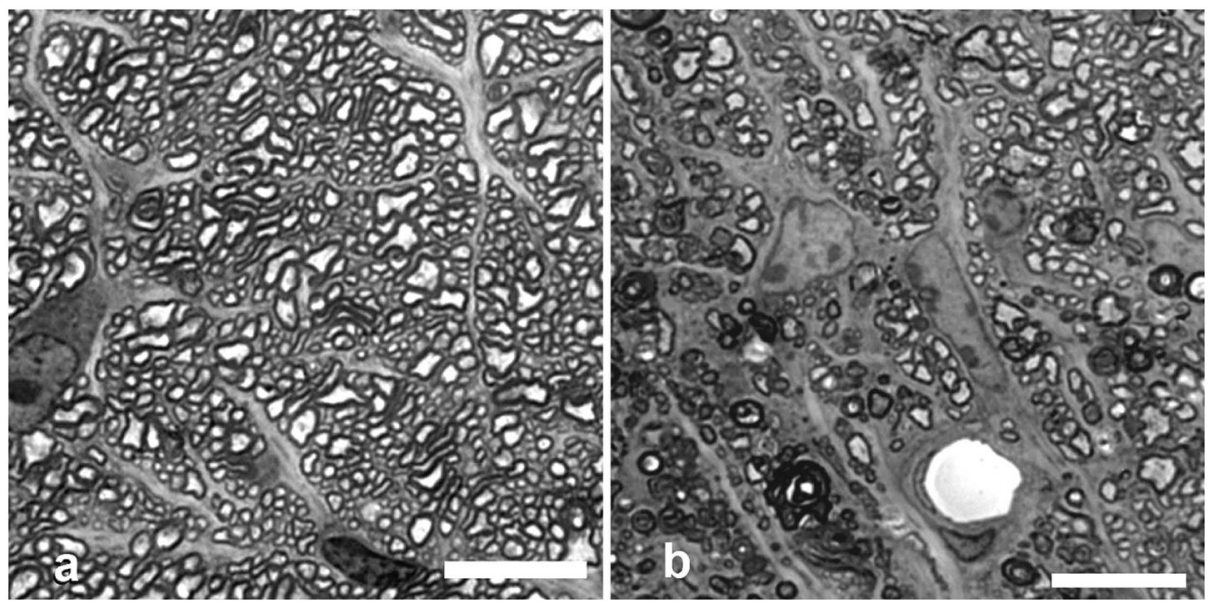

Fig. 13.

Representative images of optic nerve cross sections stained with Toluidine Blue. (A) The untreated nerve from a B6 mouse shows no damage. (B) Six weeks after intracameral polystyrene bead injection, the axons of RGCs show substantial loss and damage. (scale bar $=30 \mu \mathrm{m})$ 


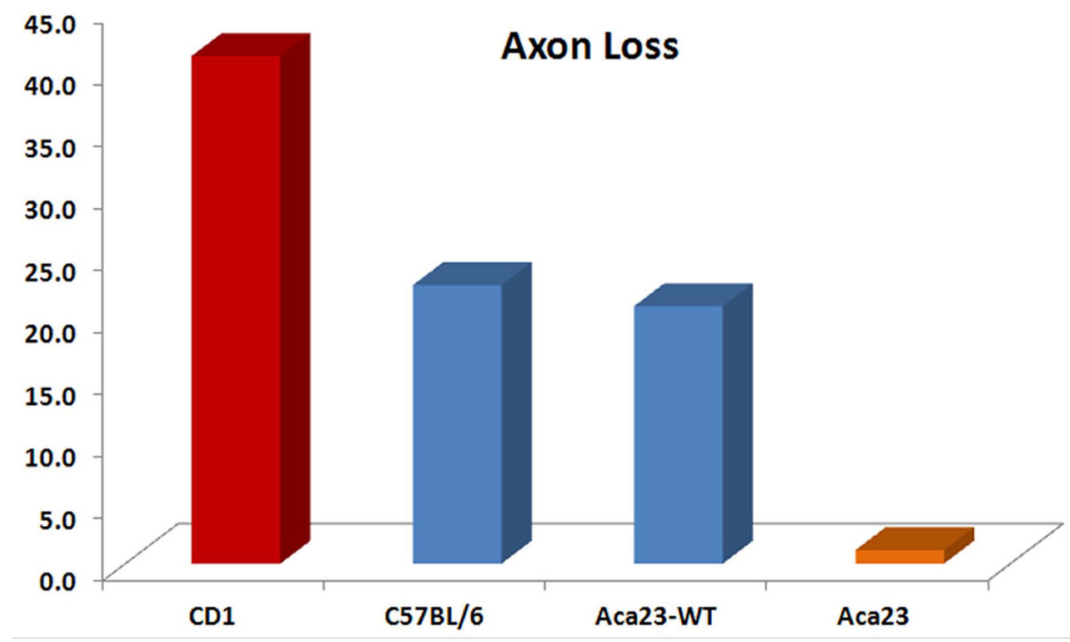

Fig. 14.

Graph shows mean axon loss for different strains of mice treated with experimental glaucoma; CD1, B6, Aca23 mutant animals and WT littermate controls (also B6 strain). Differences are highly significant between CD1 and B6/WT and between Aca23 and B6/ WT. 


\section{Fluorescent Recovery After Photobleaching}

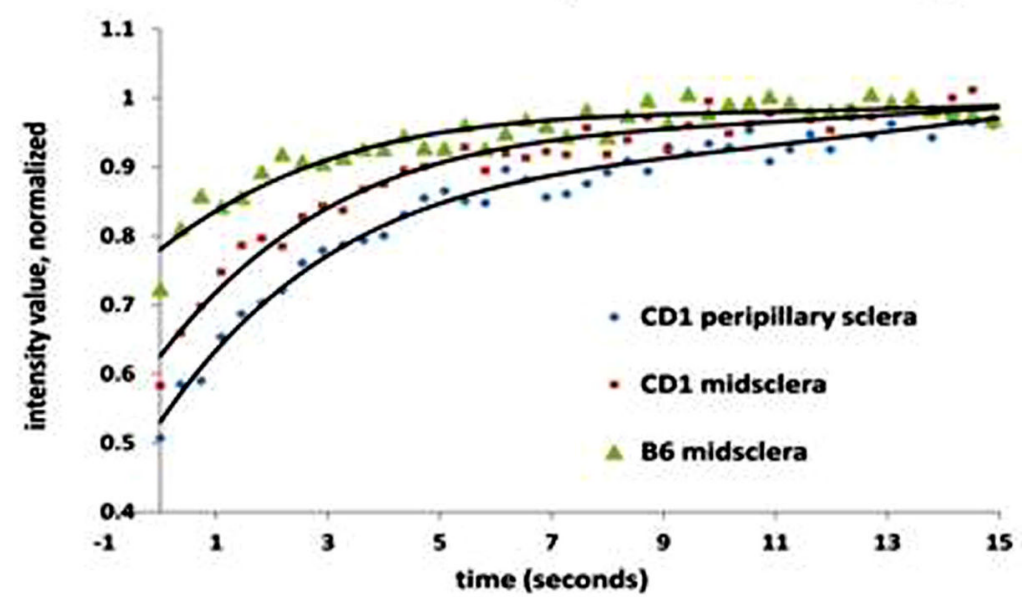

Fig. 15.

Using the method of fluorescence recovery after photobleaching, the diffusivity of sclera can be measured by the speed of return of fluoresceinated dextran molecules into a bleached zone by confocal microscopy. As shown here, the slowest return was in the peripapillary sclera (CD1 mice) compared to the mid-sclera in CD1, indicating a more compact connective tissue in the normal circumstance near the optic nerve head (lowest curve). There was also a significant difference between mouse types, with slower diffusivity in CD1 compared to B6 in mid-sclera (upper two curves). 

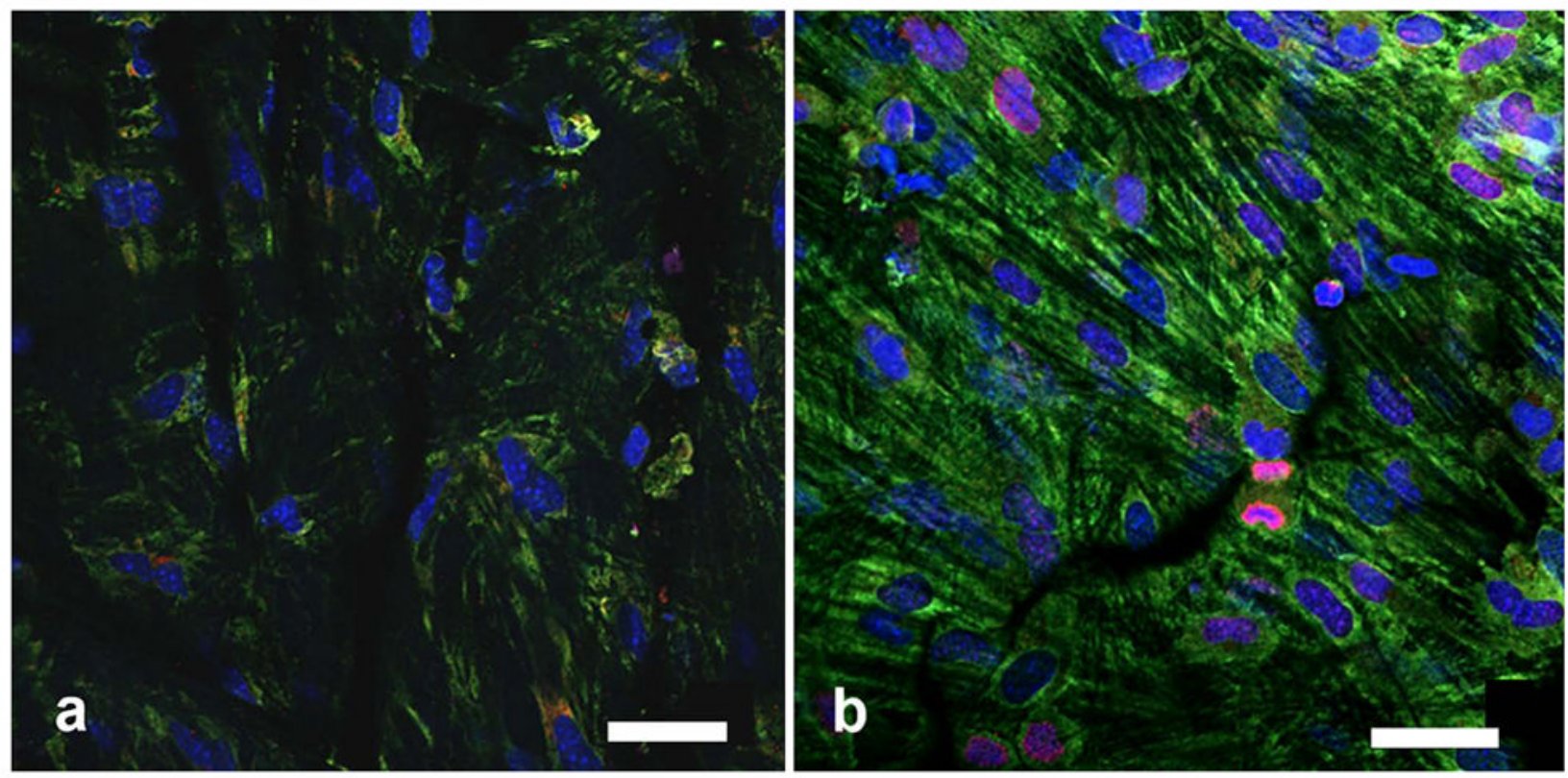

Fig. 16.

Sclera whole mounts at the peripapillary region were stained with DAPI (blue), and labeled for alpha smooth muscle actin (green) and Ki67 (red) to identify cell division. A) untreated sclera B) 3 day treated experimental glaucoma sclera. Ki67 label is greater in B, as is alpha smooth muscle actin label, indicating transition to myofibroblasts (Scale bar $=30 \mu \mathrm{m}$ ) 